\title{
ECOENERGY TOURISM, STUDY INTO SOME ASPECTS OF RELATIONSHIP BETWEEN USE OF RENEWABLE ENERGY RESOURCES AND SUSTAINABLE REGIONAL AND RURAL DEVELOPMENT
}

\author{
Lorant Denes David ${ }^{1,2}$, Csilla Molnar ${ }^{2}$, Joanna Kosmaczewska ${ }^{3}$, Gyula Fodor ${ }^{4}$, \\ Martin Zsarnoczky ${ }^{5}$, Imre $\operatorname{Varga}^{6}$, Zuzana Palencikova ${ }^{1}$ \\ ${ }^{1}$ Constantine the Philosopher University in Nitra, Slovakia; ${ }^{2}$ Szent Istvan University, Hungary; \\ ${ }^{3}$ University of Economy in Bydgoszcz, Poland; ${ }^{4}$ Ferenc Rakoczi II. Transcarpathian Hungarian \\ College, Ukraine; ${ }^{5}$ Kodolanyi Janos University, Hungary; ${ }^{6}$ Eotvos Lorand University, Hungary \\ dr.david.lorant@gmail.com, molnar.csilla@gtk.szie.hu, joanna.kosmaczewska@byd.pl, \\ gyulafodor@hotmail.com, martin@kodolanyi.hu,varga.imre@ sek.elte.hu, zpalencikova@ukf.sk
}

\begin{abstract}
The use of renewable energy resources (RES) can have multiple positive effects on the development of regional and local economies. This sector has been indicating a significant and undiminished growth as well as is sensitive to maintain its environmental image. However, to sustain the sector's success, a rather complex system of environmental, economic, social and political requirements has to be fulfilled. Among them, this study intends to focus on some relevant social aspects. Public attitudes to RES are closely related to the level of knowledge on the various technologies that, in many cases, indicate perceived limitations. A display and presentation of implemented projects can be of key importance in raising this limited level of knowledge as well as in providing publicity and wide-spreading these technologies. RES-related investments and facilities have become tourist attractions at several regions worldwide. Their target audiences cannot be limited to experts, but such activities can also play an important role in environmental education. This study, based on international and Hungarian examples, intends to give a review on the extent of such potentials of the ecoenergy tourism sector exploited by the operators of implemented RES-related projects and also the possibilities of this sector be linked with other tourism development sectors. The fulfilment of various requirements and overcoming the main challenges in order to make such implemented projects as tourist products eventually contributing not only to the sector's successfulness, but also to the development of the region involved by RES investments is also investigated. Based on the conclusions drawn by the projects analysed, a great improvement potential seems to be available both regarding the elaboration of information and educational materials, and the integration of the ecoenergy tourism sector into other development objectives.
\end{abstract}

Keywords: renewable energy sources, sustainable regional and rural development, environmental education, sample projects, ecoenergy tourism.

\section{Introduction}

Urbanisation processes impact rural areas through causing economic, social and environmental problems. To deal with such challenges, innovative solutions tailored to disadvantaged rural areas [1] are essential. These solutions also have to be future-oriented and viable that orientation requires a "new way of thinking" [2] as well as have to be guided by appropriate measures of sustainability [3]. This creative process must be based on extended, effective communication and cooperation. Only intensive interactions among the participants of the development process may bring positive developmental outcomes [4]. Hungarian precedents indicate that settlements with rational development directions designated by a well trained person for the communities involved are capable of successful development [5].

The use of renewable energy sources has become one of the development measures in backward regions through improving the living conditions of the residents and the population-retaining capacity of rural areas by establishing new jobs, fostering sustainable agriculture and positively affecting complementary industries (chemical industry, agricultural machinery etc.).

Developments related to RES-based energy supply systems can be considered as corresponding with such trends, however, the wide-spreading of these technologies is often hindered by low public acceptance. It is usually resulted from the lack of adequate information or disinformation and can also be contributed by unacquired uncertainty or resistance related to all sorts of novelties addressing the 'new' unlike the given technology [6]. As a primary precondition for the success of such investments, residents of the regions involved should be acquainted with the benefits (as well as the disadvantages) of the technology to be applied along with the potentially most comprehensive and exact knowledge on the goals, advantages and costs related to the investment. 
As the residents' incomplete knowledge and disinformation can be manifested in a negative, hindering public opinion towards future investments, and furthermore, due to the lack of environmentally conscious attitude, otherwise beneficial and useful investments can be cancelled impacting the given region's socio-economic conditions.

Based on the above, the assumption according to which knowledge-driven economy has a greater effect on the quality of life compared to traditional economy [7] is also underlined.

\section{Materials and methods}

This study intends to provide a comprehensive review on the concept and essence of ecoenergy tourism. First, the concept's explanation and the branch's impoundment along with the introduction of its regional and rural development aspects are described. This is followed by an analysis of the elements of the causemaps required to the successful functioning of this industry with special focus on the demand side. Based on international and Hungarian examples, a review on the extent of such potentials of the ecoenergy tourism sector is exploited by the operators of implemented RES-related projects and also the possibilities of this sector be linked with other tourism development sectors will be given. The fulfilment of various requirements and overcoming the main challenges in order to make such implemented projects as tourist products eventually contributing not only to the sector's successfulness, but also to the development of the regions involved by RES investments is also investigated.

\section{Results and discussion}

Ecoenergy tourism is referred to as a branch of tourism with its attraction including facilities and devices using renewable energy sources. It aims at fostering popularisation and wide-spreading of energy efficiency solutions and RES-related technologies through providing information and educational activities. By the above, it can contribute to the development of the regions involved and rational and effective management of their resources [8].

The position of renewable energy sources as a development possibility can be improved in several regions by integrating this priority into tourism development projects as the latter ones usually have a leading role among development priorities. As to relevant RES facilities, venues suitable for giving place for conferences and workshops are attached, by their exploitation, the prospering of professional tourism and conference tourism is also foreseen.

As indicated by recent tendencies and figures, the use of alternative fuels has been increasing worldwide and consequently the number of investments is also likely to grow. It represents challenges that also require reactions from the energy industry as well as from other sectors (e.g., tourism, media).

RES-related investments and facilities have become tourist attractions at several regions worldwide. Even thematic routes linking such attractions are established. On the territorial level, such routes are included in the context of energy regions that can be classified to many groups (energy region, ecoenergy region, energy valley etc.). Their products can be developed based on various institutional backgrounds [9] and mainly attract experts. Such visits and orientations not only offer excellent opportunities for re-training and getting acquainted with more recent technological innovations, but also give an introduction to the potential use of renewable energy sources for laymen and actors involved in the relevant education fields. Therefore, target audiences, as indicated in Fig. 1, cannot be limited to experts, but activities taking place at the related attractions can also play an important role in environmental education (referred to as expert oriented and experience oriented energy tourism [9], respectively).

Ecoenergy tourism as a relevant segment of environmental education can be present at elementary and secondary schools, at the higher educational level as well as outside schools. The content of environmental education has recently broadened worldwide and now focuses on sustainability and securing the future of mankind. Its main energy-related aspects (energy saving, energy efficiency, the use of renewable energy sources and alternative fuels) are summarised and visualised in Fig. 2. 


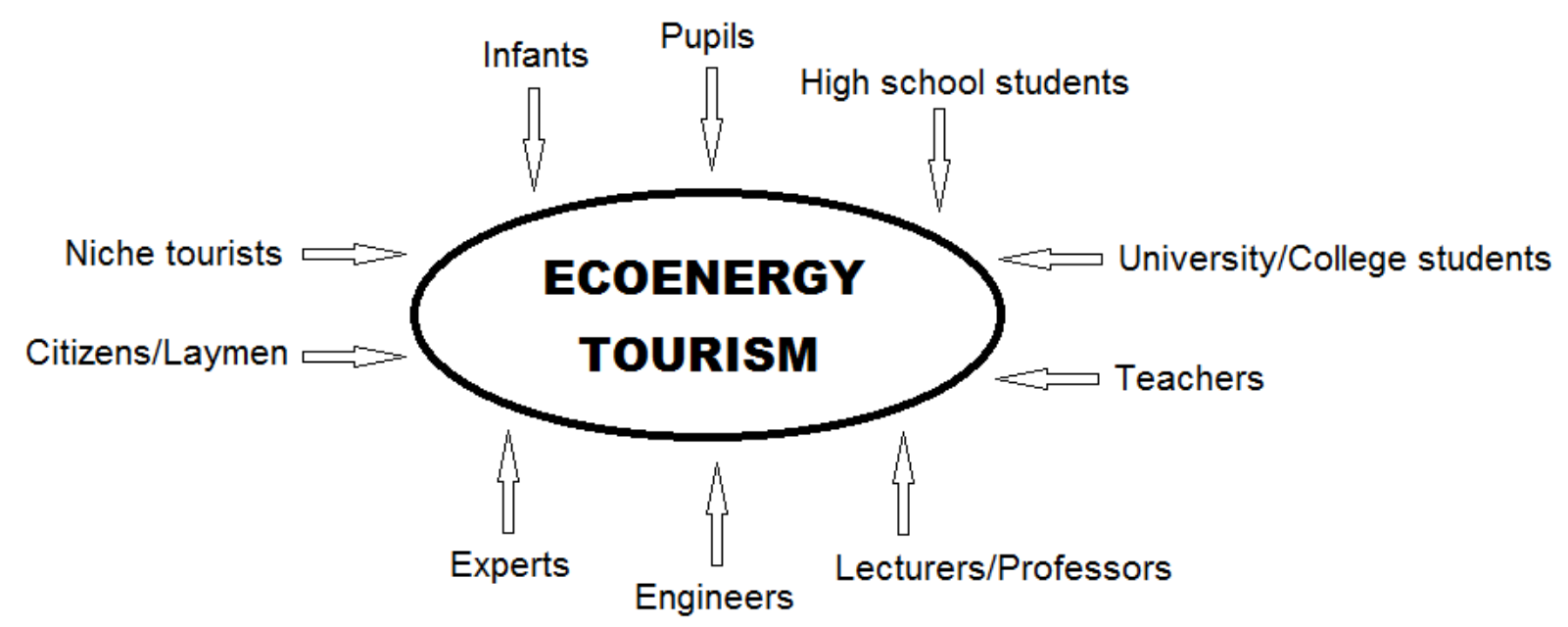

Fig. 1. Target groups of ecoenergy tourism (own compilation)

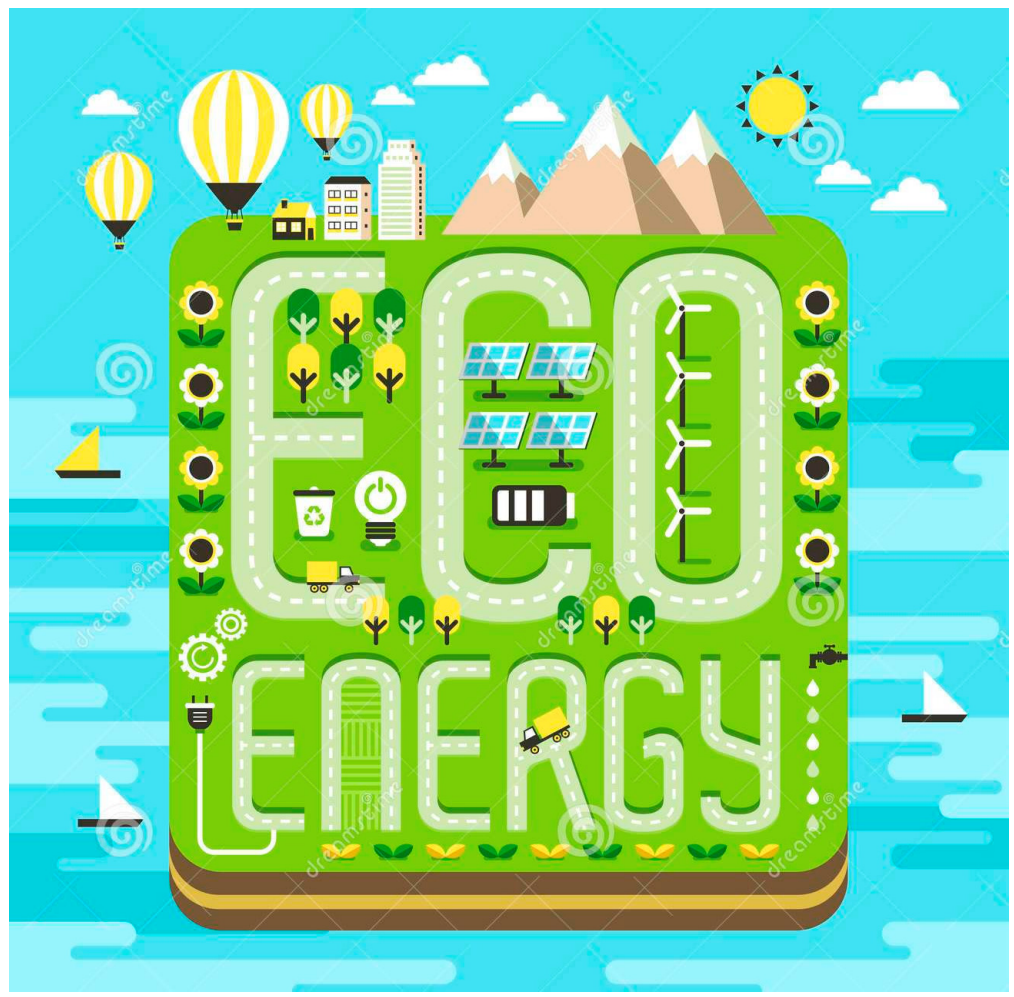

Fig. 2. Example of visualised summarisation of ecoenergy issues [10]

Consequently, an apparent task in public education is to integrate RES-related knowledge into elementary school curriculum and intensify this knowledge in secondary schools. The objectives set for the above can have a broad range including training for practicality and introduction of environmentally friendly and cost-effective technologies etc. However, it is important to note that graduating students should be aware of the essentials and main advantages of these innovations, by which a considerable contribution to the energy-conscious development of society can be made.

Environmental education related to the field of renewable energy sources should include the potentially most comprehensive transfer of knowledge tailored to the characteristics of age groups involved and thus should be manifested by the development of a rational approach. Educators familiarise students with the significance of the environmental benefits resultant from the use of alternative fuels as well as the positive impact of utilising local resources. This activity can be considerably advanced, if educational institutes take advantage of possibilities offered by heat power plants, wind turbines or hydro power plants and one-day visits for students can be arranged. Moreover, one-week-long thematic camps can also be an effective tool for the awareness-raising of younger 
generations. A precondition according to which environmental actions of average residents should be driven by inner motivations can be more easily fulfilled by the acquaintance learnt at such camps. This is especially important as related activities focus on future energy users and the strengthening of their level of environmental consciousness could increase the current usage rate of 'green products' (including 'green energy') in the future. As indicated by international precedents, despite youngsters surveyed acquire a demand for such changes, the price of energy generated from renewable energy sources represents a significant hindering factor [11].

Teachers play a key role in educating renewable energy resources related knowledge. Through organised vocational trainings and re-trainings, the educators' relevant activity can be facilitated resulting in a more effective transfer of rational knowledge related to the topic tailored to the requirements of the age groups involved.

The relationship between sustainable development and information society has recently become unquestionable [12]. The relationship between RES-related education and the use of the Internet is discussed in several studies. The potentials offered by the web are basically inexhaustible, thus Internet-based education can become beneficial in many ways (greater flexibility, easier and more rapid communication, access, etc.). The potentials in organising virtual study trips that mainly facilitate the reduction of greater distances and thus the decrease of related costs is also widely described. In the meantime, it is also important to note that virtual events cannot entirely replace the functions fulfilled by actual study visits.

Environmental education outside schools, with its activities focusing on e.g. providing information to residents and political decision-makers involved in the given project can also be of key importance. In case communication on visual impacts (through presentation of real panorama images, 3D graphics) with residents is conducted, itis usuallydecisive regarding project implementation as by such activities public acceptance can be increased and the decision-making process can also be facilitated [13]. The involvement of local residents is mentioned by several authors (e.g., [14]) as a key factor for successful implementation of RES-related projects.

Providing information, however, should be interpreted in a broader context with involving not only a given technology or the renewable energy sector itself, but should be extended to include target groups asfarmers intended to grow energy crops as well as residentsinterested in energy efficiency and energy saving issues or reconstruction of heating systems. The main elements and activities related to ecoenergy tourism discussed above are summarised in Fig. 3.
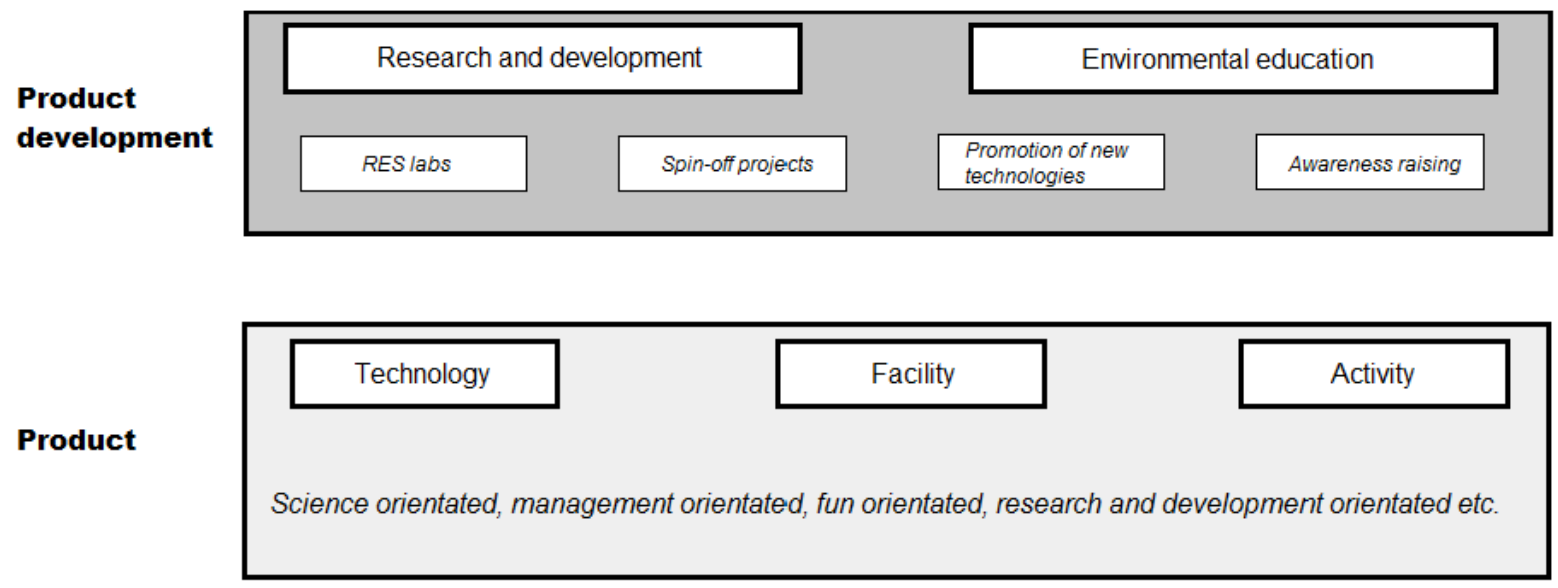

Users

Expert orientated ecoenergy tourism

Experience orientated ecoenergy tourism

Fig. 3. Content of ecoenergy tourism, edited based on [9] and [15]

The Town of Güssing located in Austria, where a heat power plant and several alternative energy projects gaining distinction in Europe have become an important destination of professionals, can be regarded as a prototype of the ecoenergytourism concept. Güssing was Austria's first energy self sufficient city and its innovative energy concept resulted in a sustainable regional development 
process with more than 50 new enterprises established creating more than 1,000 direct and indirect jobs in the renewable energy sector. The area attracts around 21,000 visitors per year [9]. In order to satisfy the demands, guided visits are organised, where details of the developments along with the technologies applied, costs and other information are presented by trained assistants [8].

The development of the project Alcoutim Solar Demonstration Platform in Portugal started in 2010. The platform's innovative infrastructure services and "Plug \& Produce" model offer various technology companies conditions of excellence for testing, demonstration, and commercialisation of the wide range of solar technologies, and investors with 'ready-to-invest' projects [15]. In this case, innovative solutions can be a potential factor based on the attraction itself developed.

RES facilities installed in Hungary during the early- and mid-2000s have become, to various extents, tourism attractions. The village of Kulcs that, according to the opinions of its residents, gained nationwide recognition due to the installed wind turbine with a capacity of $600 \mathrm{~kW}$ can be mentioned as a good example. At the village of Bükkaranyos, at an enterprise's property also functioning as a demonstration site, courses on the use of renewable energy sources were intended to be launched. Their main audience that included both professionals as well as other actors (students, academics, etc.) intended to get acquainted with the facilities and obtain detailed knowledge on the investment on site [8]. Some relevant good practices from Szeklerland (in Transylvania, Romania) have been presented in our previous study [16].

In recent years, several high capacity solar power plants have been installed in Hungary. Such sites located at Paks and Felsőzsolca, due their size (76,500 and 74,000 PV panels, respectively) and installed capacity (ca. $20 \mathrm{MW}$ ) [17], are also suitable for establishing ecotourism sample projects.

Although, in many cases [18] energy consumption issues of the tourism industry are emphasized, international literature [19-21] is increasingly focusing on the opportunities discussed above in this study. The topic also seems to attract the interest of researchers of various fields worldwide with several R\&D projects in preparatory phase and under implementation in the countries of Central Europe (Hungary, Slovakia, Poland. Ukraine). Our cooperation will be very important in the near future for ecoenergy use and ecoenergy tourism development as well.

\section{Conclusions}

The apparent demands, manifested in the increased wide-spreading of the use of renewable energy sources, the need of related environmental awareness raising, the interest of experts as well as the potential economic advantages (fostering of professional and conference tourism, attraction of potential investors) definitely underline the raison d'étre of ecoenergy tourism sector. To its successful development, several objectives as preconditions have to be fulfilled. Among them, the relevance of the following can be emphasised:

1. Designation of target areas and pilot projects for the various branches of the renewable energy sector are required with the establishment of cooperation among the stakeholders.

2. Based on surveying of the demand for such activities, along with the potential target groups, syllabus of information and educational materials tailored to the requirements of the target groups should be elaborated.

3. Possibilities to organise school visits and thematic camps with various time range are required to be analysed.

4. Establishment of a coordination and cooperation centre fulfilling management and supervision functions and connected with decision-makers and institutions can also be advantageous.

5. To implement the above-mentioned actions, a quest for investors is also indispensable.

The complexity of the described challenges assume joint actions to be taken in order to successfully exploit the advantages offered by the ecoenergy tourism sector in contributing to the development of backward rural areas.

\section{References}

[1] Nagy H., Káposzta J.,Varga-Nagy A. Is ICT smartness possible development way for Hungarian rural areas? Proceedings of the 17th International Scientific Conference Engineering for Rural Development, 2018, pp. 463-469. 
[2] Bujdosó Z., Kovács T., Szücs Cs., BrambauerZs. "New"direction of urban development from a Central European perspectives. Theoretical and empirical researches in urban management,vol. 11 (2), 2016, pp. 55-64.

[3] Molnár A., Singh, M.K., Nagy, H., Percze, A. Barriers and opportunities of sustainable bioenergy production in Hungary. Cereal Research Communication, vol. 35 (2), 2007, pp. 793-796.

[4] Liebmann H., Robischon, T. StädtischeKreativität: Ein Potenzialfür den Umgangmi tSchrumpfungsprozessen. In: H. Liebmann T. Robischon T. (Ed.) StädtischeKreativität Potenzialfür den Stadtumbau. InstitutfürRegionalentwicklung und Strukturplanung, Darmstadt, Germany: Schader-Stiftung, Erkner, 2003, pp. 6-13. (In German).

[5] Buday-Sántha A.: The contradictions of agrarian and rural development in Hungary. In: Magyar Tudomány (Hungarian Science), vol. 170 (8), 2009, pp. 937-946. (In Hungarian).

[6] Patkós Cs., Baros Z. The role of human resources in the utilization of renewable energy sources. Proceedings of the conference entitled as Cross-border cooperation, human resources, 2003, pp. 71-75. (In Hungarian) .

[7] Nagy H., Illés B., Káposzta J., Donnik I. Clusters and concentration of businesses in regions of some European countries as tools for economic development. Proceedings of the 16th International Scientific Conference Engineering for Rural Development, 2017, pp. 248-253.

[8] Dávid L., Baros Z., Bujdosó Z. The essentials and future of eco-energy tourism. Gazdálkodás (Economics), Special issue, vol. 50 (15), 2006, pp. 92-101. (In Hungarian)

[9] Jiricka A., Salak B., Eder R., Arnberger A., Pröbstl U. Energetic tourism: exploring the experience quality of renewable energies as a new sustainable tourism market. WIT Transactions on Ecology and the Environment, vol. 139, Sustainable Tourism IV, 2010, pp. 55-68.

[10] Ecology concept design. [online][16.02.2019] Available at: https://www.dreamstime.com/stockillustration-ecology-concept-design-lovely-eco-energy-island-scenery-image76320278

[11] Gossling S., Kunkel T., Schumacher K., Heck N., Birkemeyer J., Froese J., Naber N., Schliermann E. A target group-specific approach to "green" power retailing: students as consumers of renewable energy. Renewable and Sustainable Energy Reviews, vol. 9 (1), 2005, pp. 69-83.

[12] Välimäki J. The information society and the use of sustainable development indicators. Futura,vol. 2, pp. 69-75.

[13] Berg E. How to communicate visual impact from very large-scale wind energy projects to the public and the decision-makers. CD proceedings of the European Wind Energy and Conference, 2003.

[14]Devres. The socio-economic context of fuelwood use in small rural communities. Agency for International Development Evaluation Special Study,(1), 1980, 16 p.

[15]Enercoutim homepage [online][16.02.2019] Available at: http://en.enercoutim.eu/ourfocus/platform/

[16] Ambrus T., Dávid L., Artemyev A., Barczak M., Dombay S.Renewable energy sources, rural development, tourism. Proceedings of the 17th International Scientific Conference Engineering for Rural Development, 2018, pp. 1909-1915.

[17]MVM Zöld Generáció Kft (MVM Green Generation Kft) [online][16.02.2019] Available at: http://mvm.hu/bemutatkozas/mvm-csoport/mvm-hungarowind-kft/ (In Hungarian)

[18] Tourism and Sustainable Energy: Powering Sustainable Development. World Tourism Day. UNWTO 2012. [online][16.02.2019] Available at:

http://wtd.unwto.org/en/content/tourism-sustainable-energy-powering-sustainable-development

[19] Gossling S. Global Environmental Consequences of Tourism. Global Environmental Change vol. 12(4), 2002, pp. 283-302.

[20] Frew E. Industrial Tourism Theory and Implemented Strategies.In: Woodside A. (Ed.) Advances in Culture, Tourism and Hospitality Research, vol. 2, Bingley: Emerald,2008, pp. 27-42.

[21]Frantál B., Kunc J. Wind Turbines in Tourism. Landscapes: Czech Experience. Annals of Tourism Research vol. 38, 2011, pp. 499-519. 